\title{
EDITORIAL
}

\section{Promoting research among young scientists in Sri Lanka}

Scientific research and innovation are essential for national development. According to criteria commonly used to rank Science and Technology, Sri Lanka lags behind some of her neighbours. It is reported that "Sri Lanka has the lowest number of postgraduates in the science fields within the South Asia region" (World Bank, 2008). In fact, the total number of Ph.D. degrees awarded by Sri Lankan Universities in 2004 and 2006 are only nine and twenty six respectively (University Grants Commission, 2006). Further, of a total of $4520 \mathrm{R} \& \mathrm{D}$ scientists in 2006 only $25.7 \%$ had Ph.D. degrees (National Science Foundation, 2009). The reasons attributed to this low productivity include lack of demand and absence of an enabling environment. Although there are many graduates who excel in Bachelor's degree courses in science, only a relatively small number venture into scientific research, because of limited career prospects and financial remuneration, and lack of opportunities for scientific research. The National Science Foundation of Sri Lanka, a major organization funding scientific research in the country, awarded 10 and 12 research scholarships in 2004 and 2005 respectively, but no scholarships were awarded in subsequent years due to decreased allocation of government funds. Allocation of funds for research, especially those leading to higher degrees, is essential to create an environment conducive to research and prevent highly skilled young graduates from seeking employment in other professions which are more attractive, such as management and business, or in research positions in developed countries.

Senior scientists can play a pivotal role in promoting research among young scientists, as they have the ability to access resources for research and also guide young researchers. Identifying research projects of special relevance to Sri Lanka will ensure provision of funds and facilities for continuing research. Greater interaction between universities, research institutes and the industry is likely to facilitate support for high impact research. There are many young graduates employed in research institutes in Sri Lanka, but most tend to undertake only routine work and are not motivated, or lack opportunities to carry out research at a higher level, especially those leading to higher degrees. Senior researchers should serve as mentors to guide young scientists to identify research problems and undertake high quality research. In fact, many science academies worldwide, including the Inter Academy Panel (IAP), the global network of science academies, have initiated programmes to promote research and scientific dialogue among young scientists. This has culminated in the establishment of the Global Young Academy (GYA) which aims to promote science as a career choice for young people, expand research capacity, encourage novel approaches to solve scientific problems of international significance and exchange best practices in science policy and education (Editorial, Science, April 2010).

Young scientists often communicate their research findings at local and international meetings and then proceed to submit their dissertations for research degrees. However, only a few publish their work in peer reviewed journals. It is necessary to motivate and guide young scientists to publish their work in indexed journals, as acceptance for publication in a reputed journal would not only help to disseminate research findings, but also to enhance the value of the research. With recent advances in computer technology there is increased access to good quality scientific journals and all research students should be encouraged to read journal articles regularly, not only to keep abreast of advances in research, but also to acquire writing skills. It is essential for young scientists to attend courses/workshops on scientific writing during their postgraduate training. Research papers submitted for publication by some young scientists are not accepted because the content and presentation is of low quality. Senior scientists who are supervisors and co-authors should guide their research students in preparing manuscripts for publication. In some universities, evidence of acceptance of at least one research paper in an indexed journal is a requirement prior to submission of the thesis, to ensure that research carried out for a higher degree leads to one or more publications.

Many young researchers carry out high quality research for M.Phil./Ph.D. degrees, but do not continue their research after obtaining postgraduate degrees. Although evidence of research is necessary for career 
advancement in universities, it is less important in research institutes. It is necessary to motivate scientists in universities and in research institutes to continue scientific research and publish their work. Introduction of Presidential Awards for Research and other research awards is likely to be an incentive to promote research. It is also necessary to facilitate the utilization of research findings for national development. Such an approach is likely to serve as an impetus for young scientists to continue their research.

Sunethra Atukorala 